\title{
The Control of Water Logging in Kunming Based on Combined Utilization of Rainwater and Rain Energy
}

\author{
Yu-chao $\mathrm{CHEN}^{\mathrm{a}}$, Shi-hua $\mathrm{HE}^{\mathrm{b}}$ and Ji-min $\mathrm{HU}^{\mathrm{c}}$ \\ Faculty of Electric Power Engineering, Kunming University of Science and Technology, Kunming, \\ Yunnan, 650500, China \\ a1328356948@qq.com, bhoxiwa@aliyun.com, '814514111@qq.com
}

Keywords: water logging; water environment; rainwater utilization; rain energy

Abstract: In view of the serious water logging, water scarcity and water environment deterioration, the paper analyzed the causes of water logging according to the specific conditions of Kunming. The problems of water logging and water scarcity were considered from the perspective of rainwater utilization. Based on analyzing the utilization and transformation of the roof, ground and underground water, the formation of a complete water collection system can directly use part of the rainwater, the other part of the rainwater can be converted to renewable energy. The combined use mode of rainwater and rain energy provides a new way of thinking for Kunming water logging treatment

\section{Introduction}

With the rapid development of urbanization, the modernization of urban construction has brought more convenience to our lives, and people's living standards are generally improved, but the high-rise buildings and the clean road also occupy the green land. The impervious city area expanded rapidly and hindered the rainwater infiltration. Once a heavy rain occurs in a short period of time, the water logging is easily formed due to rainwater retention, especially in the more low-lying terrains and less drainage pipe areas. In recent years, water logging has spread from coastal areas to inland. Kunming is also no exception.

Kunming is located in the central part of Yunnan Province. From the point of view of water quantity in Kunming, the total amount of water resources is considerable, but the amount of water resources per capita is insufficient. From the point of view of water quality, even controlling the pollutants emissions, industrial, agricultural and domestic pollutants discharging into Dianchi Lake are still far beyond the water environment capacity of the lake. Because of Kunming's special geographical location near the mountain lake, the occurrence of water logging has been more frequent.

\section{Water Logging Incentives}

Urban Construction. (1) Because of the acceleration process of urbanization, a large number of urban green spaces have been replaced by hardened pavement. The proportion of impervious area has been increasing year by year. If encountering heavy rain, the rainwater cannot rely on the ground infiltration, but on water pipe drainage. When the total amount of rainwater beyond the pipe drainage capacity, the rainwater will gather on the ground to form water logging.

(2) A scientific and rational drainage system of underground pipe network which is in line with urban development requirements has not yet formed in Kunming. Underground drainage pipe network is often subject to some damage, but also there are some road drainage pipe network construction is imperfect. There are some roads that do not even supporting the construction situation of drainage pipe network. In addition, the drainage network in Kunming has many other problems. The pipes which were built 50 years ago are still in use. Some drainage networks are not in place, and the layout is unreasonable. The drainage capacity also does not match with the catchment area.

(3) The transformation of local areas, such as the transformation of villages, results in the temporary poor drainage and flood formation. Before the transformation of urban villages, the sewage ditches are self-dug and difficult to access the city pipe network, so a lot of sewage discharges into the natural river 
and pollutes the water. In the process of reconstruction of the village, the connection between underground pipeline and urban drainage network is poor.

(4) Railway and subway construction destroyed the original drainage system. Railway and subway will cover the entire city of Kunming and is a huge project to bring convenience to the residents of the Kunming city, but also destroyed the underground drainage pipeline and leaded to water logging prone to occur.

(5) The old Kunming city has been using the rain and sewage combined flow system. Because the trunk pipe size is too large and the sewage capacity is also increased a lot, construction and operating costs are correspondingly increased. As a closed-flow system, part of the mixed sewage directly discharges into the water through the overflow well and results in the water also subject to polluted. Rain and sewage confluence led to the drainage pipe blockage.

Geographical Environment. (1) Kunming city area is surrounded on three sides by mountains and faces the Dianchi Lake. The catchment area of the lake basin is $2920 \mathrm{~km}^{2}$. There are more than 30 rivers flowing directly into the Dianchi Lake, but most of the rivers have small catchment area and flow through the Kunming city. The low-lying urban terrain of Kunming easily leads to flooding.

(2) Rainwater and sewage of Kunming city can only discharge to the Dianchi Lake. Once the heavy rain occurs, at the same time of the sewage into the Dianchi Lake, the water levels of river downstream and Dianchi Lake rise, which easily leads to Dianchi Lake water pollution, impeded drainage and urban water logging.

Legal Provisions. The promulgated laws and regulations on urban rainwater standards, water logging prevention and control are seriously lacking in China. The relevant promulgated regulations in Yunnan are also very few and the implementation of the law is not in place. Additionally, excessive pollutants block downstream pipeline, resulting in reduced drainage capacity of pipeline. Therefore, law is the fundamental guarantee on water ecological environment protection, rehabilitation and water logging governance.

\section{Water Logging Governance from the Perspective of Rainwater Utilization}

Currently, Kunming is facing two other serious water problems except for water-logging. One is the shortage of water resources; the other is the water pollution and the increasing surface runoff. Therefore, the flood control management ideas should transform from the traditional water quantity control to attach same important to water quantity and water quality[1], promoting the gathering and use of rainwater in order to form a virtuous circle of water environment.

Collect Rain from the Source-Control Flood. (1) Green roof and wall rainwater collection. For the increasingly dense buildings in Kunming city, the green roof can greatly compensate for the destruction of the ecological environment[2]. According to statistics, the roof area of Kunming city accounts for about $70 \%$ of the total area of urban impervious. Therefore, the roof contains a huge potential for development and utilization. Green roof is particularly suitable for the construction in dense residential areas. In addition, compared to the other green space measures in city centre, low cost has become a major advantage of green roofs.

(2) Permeable ground pavement, sunken green space, biological detention facility. According to statistics, the cement road area in Kunming accounts for $8.7 \%$ of urban construction land. The road surface generates about $1.93 \times 10^{7} \mathrm{~m}^{3}$ floods one year. Green belt on both sides of the road maintenance is generally low, probably parallel to the soil, and without setting of infiltration. In the event of light rain, rainwater can be absorbed by the soil, but in the event of heavy rain, the total amount of rainwater in a short time exceeds the infiltration capacity of the soil. The rainwater will gather rapidly on the soil surface and finally gather on the impervious surface. In the case of pipe network drainage capacity is limited, water logging is ultimately formed. Therefore, it is necessary to change road pavement by using different materials in different road of city. Permeable tiles can be used in the sidewalks, pedestrian streets, bicycle lanes and suburban roads where the pressure is not large. Permeable filler material can be used between brick and brick connection. Parking lot can choose perforated concrete 
brick and brick hole can be filled with soil which is conducive to the growth of weeds. The road of park can be paved with fine gravel and cobblestone, both sides of which can also repair the ditch used to transmit rain. When the strength and stability of the roadbed of the motor vehicle are at risk, the semi-permeable pavement may be used, in which the drainage pipe or board may be provided in the permeable base of the permeable pavement.

The green space of parks, residential areas and the both sides of the road can be built into the sunken greenbelt connected to canal, forming a decentralized processing system. The overflow port on the edge of the green land can be set up and the elevation of the overflow port is generally higher than the green $50-100 \mathrm{~cm}$.

The greenbelt surrounding regional architecture and residential buildings, roads and parking lot which is serious contaminated should set bioretention facilities such as grass ditch, preparation buffer or sedimentation tank. At the same time, pretreating the rainwater runoff, removing large particles of pollutants and reducing the speed of runoff can also be used. Biological facilities should be decentralized arrangement and the scale should not be too large

(3) Transformation of underground drainage and rainwater collecting facilities. Drainage pipeline has been used for 50 years and underground had almost no water facilities in Kunming city. Aging drainage pipes, poor pipeline management and long-term rain and sewage confluence lead to pipeline congestion and low flow capacity[3]. Therefore, the following measures can be applied to solve the problem of underground drainage: (1) The quality of hardware facilities is the premise of all planning.

The PVC material pipe is a good choice. (2) Due to the intensive housing and subway construction, rain sewage diversion is obviously not work. The utility mode can be used to treat sewage and rainwater at the same time, which can not only save the underground space, but also not affect the operation of the subway and underground pipelines. (3) Sewer and underground reservoir are the best rainwater collocation. The underground reservoir is suitable for construction in residential areas, schools, parks and other places. When encountering torrential rain, the water level of sewer rises and the reservoir can accept a lot of rainwater. In dry seasons, the water in underground reservoir can flow through the sewer to the ground, forming a good water supply cycle.

Rainwater Utilization: On-site Use, Rainwater and Rain Energy Utilization. Rainwater from underground, ground and roof can be used directly. After filtering, rainwater from roof collection can be stored and used as domestic water. Reservoir for collecting underground rainwater can supply groundwater and be used as a fire demand, irrigation and urban greening for peripheral area. This is the traditional way of directly use of rain. The other important way is RWRE (Rain Water \& Rain Energy) which is combined with rainwater and rain energy. Processed with electrochemical equipment, the collected rainwater can be used directly for municipal miscellaneous water or artificial infiltration of underground water. Electricity generated from processing can be used as a small power station [4-5]. Rain energy is a green renewable resource like wind energy and solar energy, which is of great importance to reduce the adverse effects of fossil fuels. The consumed rainwater can reduce the impact load of urban drainage system, reduce the peak flow and delay the time of peak arrival, which reduces the risk of water-logging. The rain energy power generation takes advantage of height between the building and pavement.

The output of rain energy power generation is proportional to water head of hydropower station, so tall buildings have more advantages relative to low buildings. The rain energy connecting with wind and solar power generation can form joint use of a variety of renewable resources. In the end, we are able to build independent power supply system in residential areas and large buildings.

The Support of Policy and Regulations. The implementation of the technology needs the support of policy guidance and regulations. The countries whose rain flood utilization rate is higher formulate relevant laws, regulations and technical standards in the use of rainwater to promote the rainwater utilization. China is still in the legislative stage, lacks of legislative experience in the rainwater resources use, and still needs more time to perfect the rainwater use laws and regulations at the national 
level. So, Kunming can follow Germany, Japan, Australia and other countries advancing in rainwater utilization to perfect the local mandatory regulations and to solve the flood problem in Kunming as soon as possible.

\section{Conclusions}

Kunming is located in the basin surrounded on three sides by mountains and faces the Dianchi Lake. Special geographical environment and human factors make Kunming vulnerable to water-logging. In addition, Kunming also face water shortages, water quality deterioration and other issues. So, water-logging governance can't only rely on traditional thoughts and pure drainage. We need to change the traditional thinking focusing on "rules out quickly, focus on end", and establish the new thinking way of "slowly releasing, source collection, on-site use". From the rainwater development and utilization to joint use rainwater and rain energy, we doesn't only use water resources directly, but also use available rainwater to generating power and make full use of the rain energy. Rain energy is a kind of renewable clean energy resources which is conducive to recover the ecological environment and let the water-logging problem to be resolved in the largest extent.

\section{Acknowledgement}

This research was financially supported by the National Natural Science Foundation (51369013).

\section{References}

[1] Hongqiang Tan. To deal with the city waterlogging governance from the perspective of rainwater utilization,J. Calue Engineering ,(10)( 2014): 310-311

[2] Jiaxin Jiang, Yi Li, Xiaojia Bai. family. The causes and prevention countermeasures of city waterlogging,J. Industrial Water \&Wastewater ,46 (5) (2015): 13-17

[3] Wu Che, Liqin Shen, Junqi Li. New stormwater control and utilization technology in urban road design,J. Highway ,11(2008): 30-34

[4] Zhenghua Gu, Shikai Zhao, Jiao Yueteng. A new way of city construction- the joint utilization of rainwater and rain power,J. Yangtze River ,47 (10) (2016):15-19

[5] Jiajie Shen. Study on City waterlogging governance based on rainwater utilization ,J. Jiangxi Building Materials, (23) (2014): 129 